DOI: https://doi.org/10.35560/jcofarts96/379-390

و اقع تدريس آلة العود في المؤسسات التعليمية

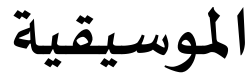

ISSN(Online) 2523-2029, ISSN(Print) 1819-5229

مجلة الأكاديمي-العدد 96-السنة 2020

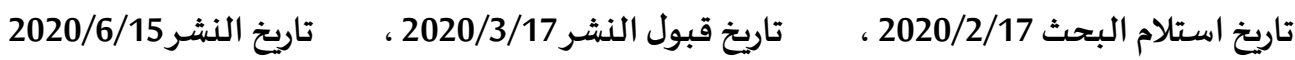
(c)

This work is licensed under a Creative Commons Attribution 4.0 International License

ملخص البحث:

تعدُ آلة العود واحدة من أهم الالات الموسيقية الشعبية في العراق، فقد عرفت منذ عصور

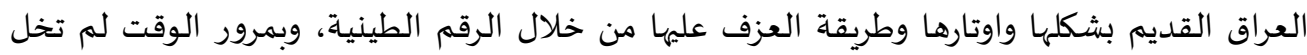

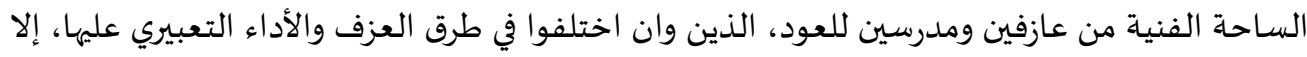

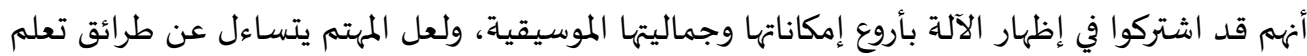
العزف على هذه الآلة، فتنوعت طرائق التدريب بين الاجتهادات الشخصية من جهاة والتدريس المنهجي في

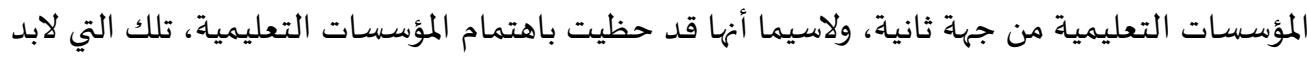
ان تنتهج استراتيجية مناسبة وعلمية تواكب مشروعات التربية العالمية في أساليب وطرائق التدريس باتس

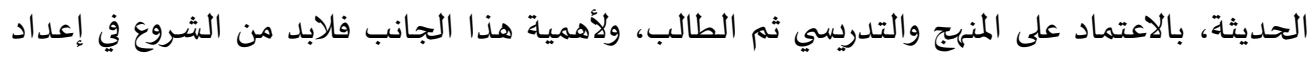

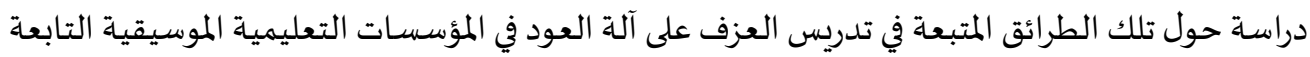

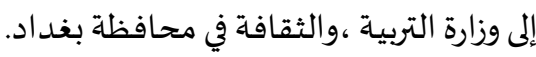
الكلمات المفتاحية: العود، تدريس العود، و اقع تدريس، مؤسسـات موسيقية.

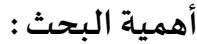

تعد المؤسسات التعليمية أحد أهم القطاعات في المجال الثقافي التي تؤدي وظيفة مهمة وأساسية

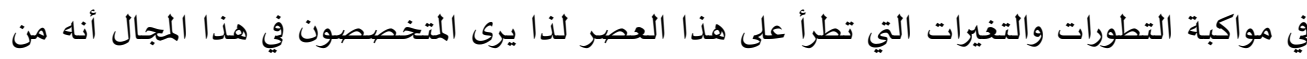
(Simon, الضروري بناء نظام تربوي جديد يهدف إلى خلق جيل قادر على فهم هذه التغيرات واستيعابهات هنيها

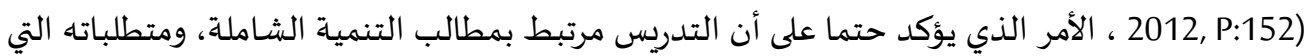
تحقق الأفضل . تمتاز آلة العود بأهمية ومكانة بين الآلات الموسيقية، بقدراتها النغمية وامكاناتها الادائية المختلفة بحسب طرق العزف عليها، وانفرد عازفي آلة العود العراقيين بإمكانات وطرائق عزف نقلوها الى الأجيال التي تلتهم بعد أن اتقنوا وأضافوا اليها ما تعلموه من أسلافهم من الموسيقيين، وقد تنوعت عاندي تلك الطرائق في نقل

1 طالب دراسات عليا/ كلية الفنون الجميلة /جامعة بغداد، .ula_hussen@yahoo.com. 
مهند رسن مجبل و اقع تدريس آلة العود في المؤسسـات التعليمية الموسيقية..

ISSN(Online) 2523-2029, ISSN(Print) 1819-5229 مجلة الأكاديمي-العدد 96-السنة 2020

وتعليم مبادىء العزف على آلة العود بشكل شفاهي، غير أن تطور اساليب وتقنيات التدريس والتعليم

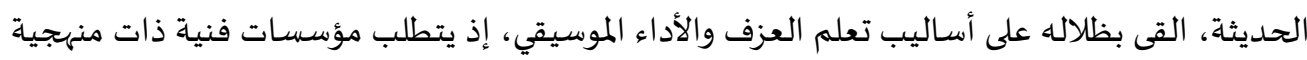

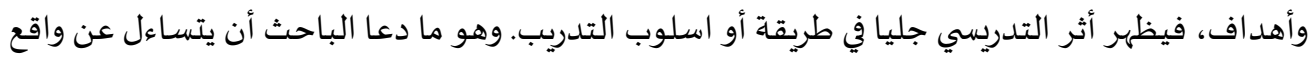

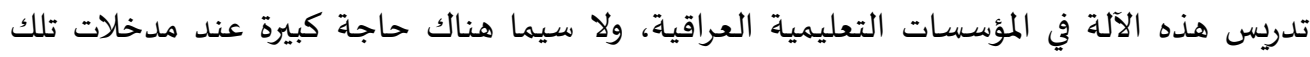
المؤسسات في تعلم عزف الة العود. وعلى هذا الاساس فقد حدد الباد الباحث تساؤله فيما يأتي : " كيف يسيرو اقع تعليم العزف على الة العود في مؤسسـاتنا الموسيقية" ؟ تكمن أهمية البحث فيما يمكن استخدامه في تطوير الواقع التعليمي للمؤسسات التعليمية

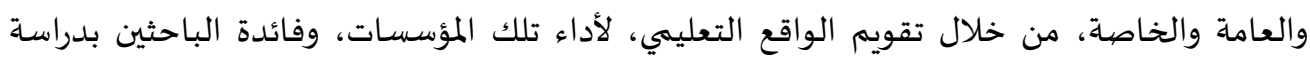
منهجية وعلمية في هذا المجال . أما هدف البحث في هذه الدراسة فيكمن في التعرف على واقع حال تدريس آلة العود في المؤسسات

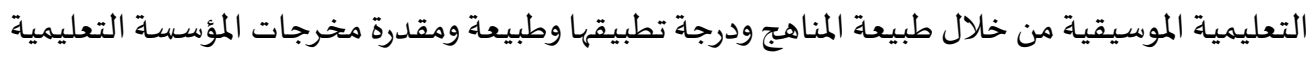

$$
\text { حن الطلاب ودورهم في المجتمع مستقبلا . }
$$

الحد المكاني : العراق - بغداد، مؤسسـات التعليم الموسيقي التابعة إلى وزارتي التربية والثقافة.

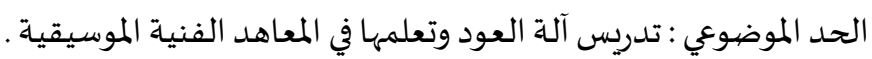

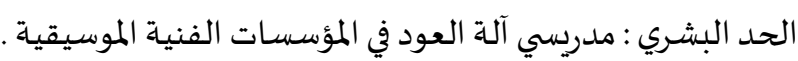
تحديد المصبطلحات : واقع : التعريف اصطلاحا : يعرفه احمد مختار بأنه " حاصل وحقيقة والامر الواقع والوضع الواقعي او الفعلي " . (Ahmed Mukhtar, 2008, P:375) التعريف الاجر ائي : مأمان هو ما موجود فعلا في خطوات واجراءات تتعلق بتدريس الة العود في المؤسسات الفنية للتعليم الموسيقي .

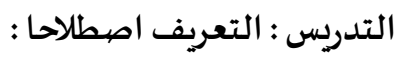
يعرفه حسين قدوري "عملية تربوية ثقافية ترفيهيه، تندرج ضمن مفهوم التربية الجمالية، تتناول الانسان

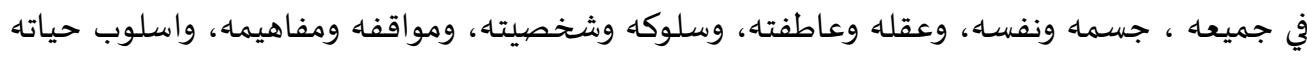
وطرائق تفكيره.

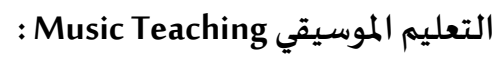
أما يودكن، Yudkin ) فيَعُدُّ التعليمَ الموسيقي " حقل من الدراسة المرتبطة بتعليم وتعلّم الموسيقى.

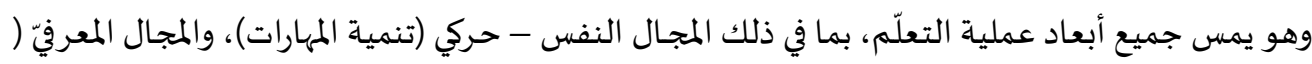

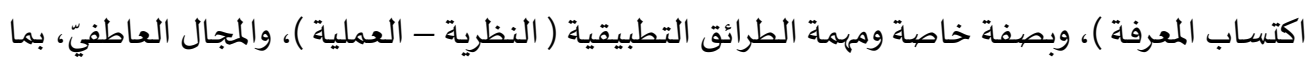

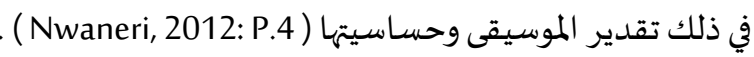


مهند رسن مجبل و اقع تدريس آلة العود في المؤسسـات التعليمية الموسيقية..

ISSN(Online) 2523-2029, ISSN(Print) 1819-5229 مجلة الأكاديمي-العدد 96-السنة 2020

التعريف الاجر ائي :

هو عملية تربوية ثقافية ، يمارسها التدريسي بهدف نقل ما في ذهنه من مهارات ومعارف ومعلومات تخص تدريس آلة العود إلى الطالب وفق رؤيا ومنهج متسلسل نظويله ، ئمارسيا وعمليا .

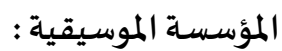
هي منظمة تم تأسيسها من أجل تحقيق نوع من انواع الفنون الموسيقية ، ضمن أهداف ومعايير ولا سيما

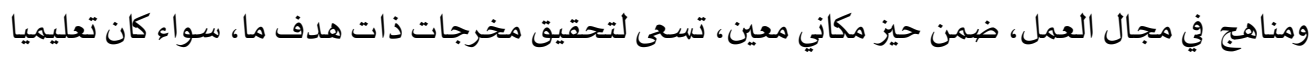

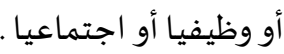
الإطار النظري دور آلة العود في المجتمع: تعد الة العود من أقدم وأهم الآلات العربية المحببة الى نفس ووجدان واذان الشعب العربي،

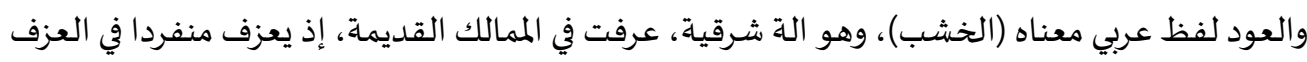
و لمرافقة الغناء، وجماعيا ضمن تشكيلات الفرق الموسيقية، ويعتمد عليه معظم الملحنين في تلحين الأغاني وتحفيظها.

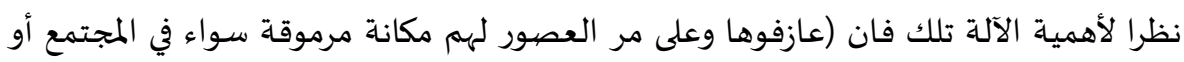

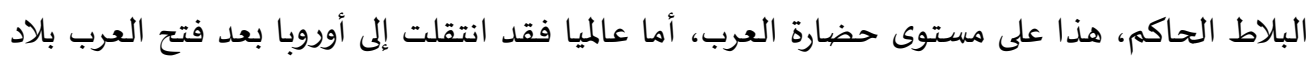

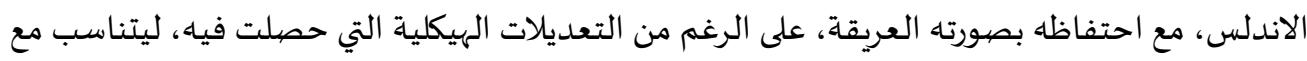

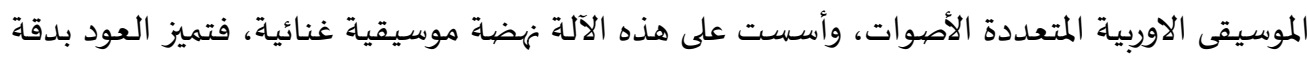

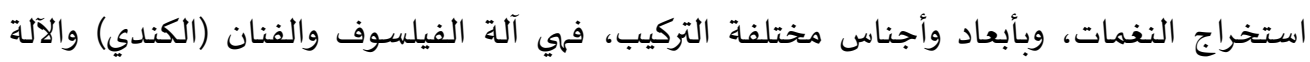

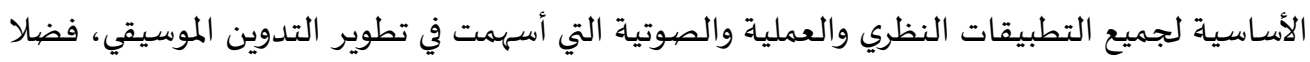

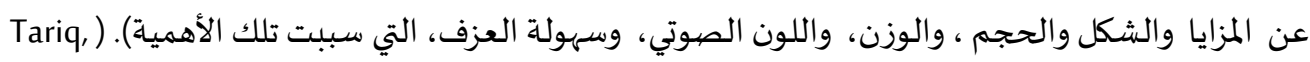
(1990, P:328

\section{تعليم العزف على العود : ت ت ت}

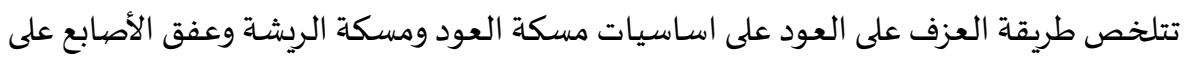

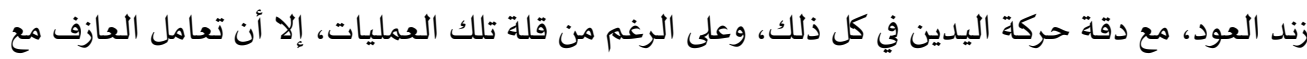

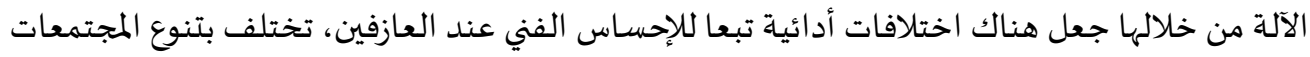

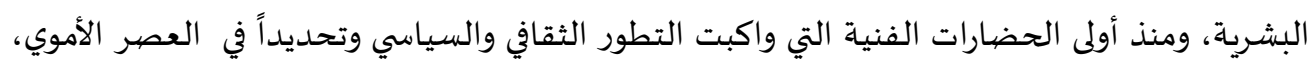

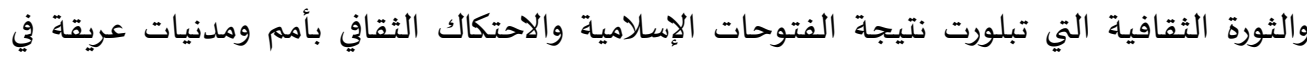

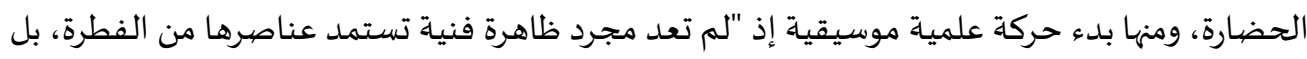

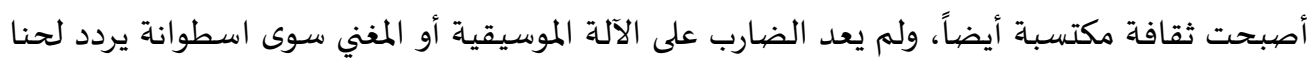
حفظه، بل كان عليه أن يعرف شيئًا عن الشعر، والملحن، وجنس النغم وإيقاعه، وغير ذلك من الأخبار التي

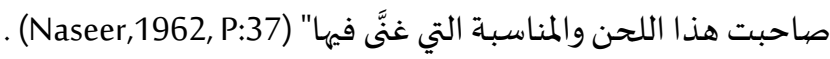


مهند رسن مجبل

تطورت آلة العود في بداية القرن العشرين فقد أنشىء معهد الموسيقى العبية عام 1932 م

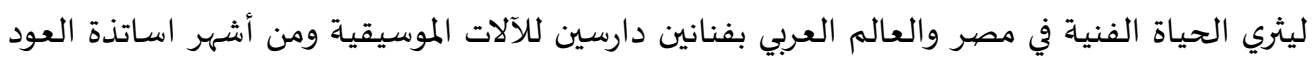
ورواده مثل (رياض السنباطي، ومحمد القصببجي، ومحمد عبد الوهاب، وعبد الفتاح صبري )... وغيرهم،

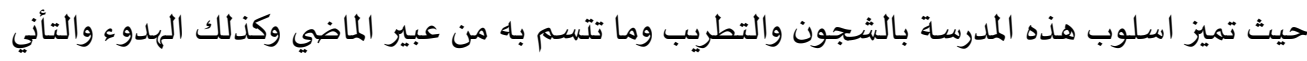

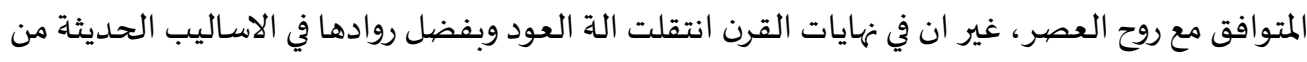

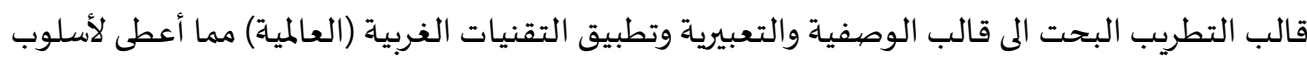
العزف والتأليف لآلة العود شكلا جديدا مختلفا عما كانت عليه من قبل، ومن أبرز العازفين فيها (فريد الاطرش، وعمار الشريعي، ومنير وجميل بشير ، ونصير شماة، وخالد الشيخ، وآخرين). مدارس آلة العود : ماكئ ظهرت مدارس آلة العود في عصرنا الحاظر، ومن أبرزها المدرسـة التركية، والمدرسة المصرية، والمدرسـة

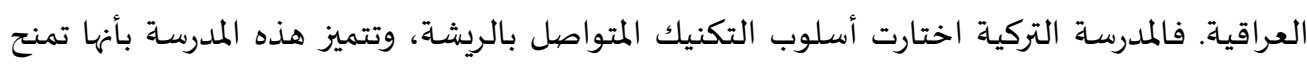

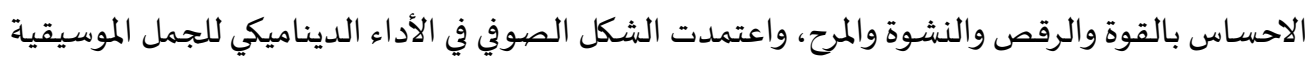

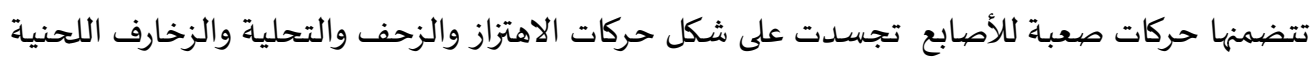

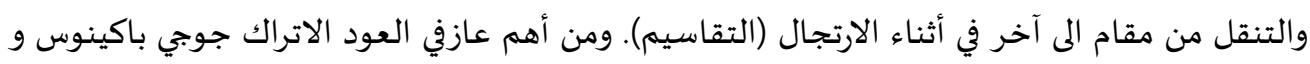
جنوجن و هرانت وياردال وغيرهم كثير. أما المدرسة المصرية للعود "فتأسست على بقايا السلطنة التركية في العزف على على هذه الآلة التي

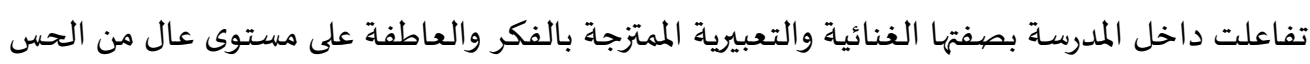

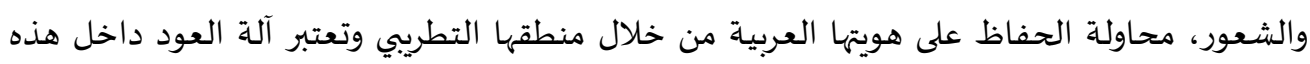

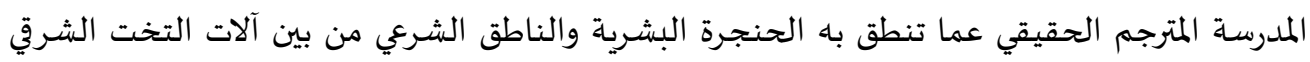
بمرافقة ومحاسبة الغناء"

(Al-abbas,2006, P:8)

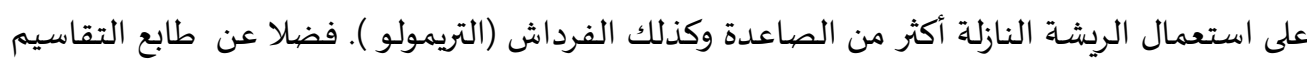

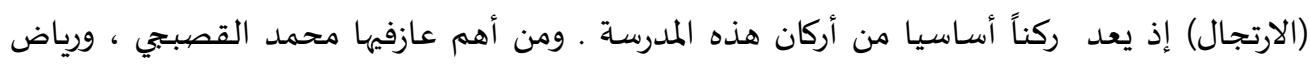

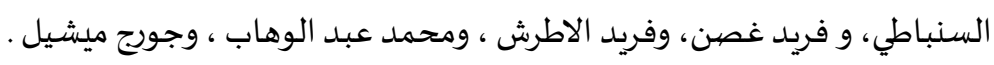

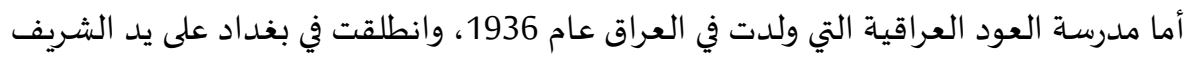

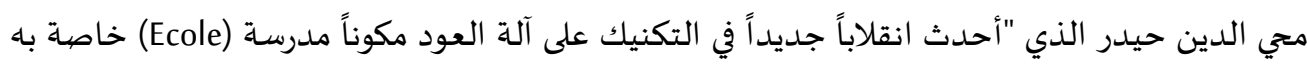
(Abdel moneim,1947, P:95)

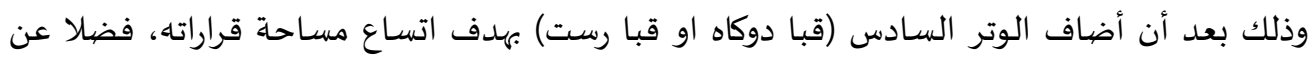

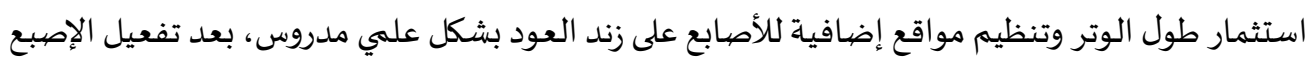
الرابع (الخنصر) وذلك بما ينسجم وطبيعة طول الوتر وعلى نحو رباضي محسوب" (Al-abbas,2006, P:10)

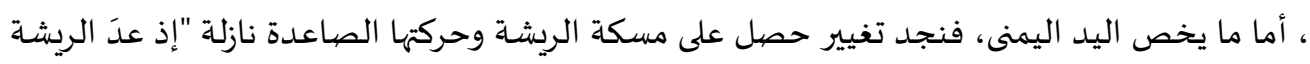
أداة فاعلة في عملية تجسيد الصيوت من خلال انجاز عزف القيم الزمنية السريعة التركيب التي تعجز التركئ 
مهند رسن مجبل و اقع تدريس آلة العود في المؤسسـات التعليمية الموسيقية..

ISSN(Online) 2523-2029, ISSN(Print) 1819-5229 مجلة الأكاديمي-العدد 96-السنة 2020

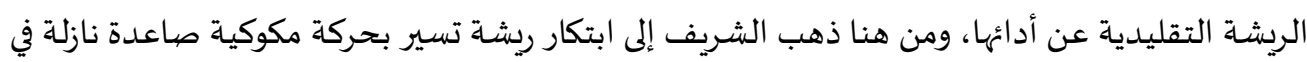

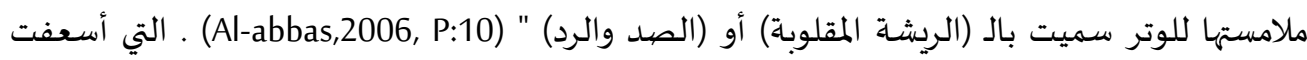
العازفين من محنة عزف المقطوعات الموسيقية الصعبة والسريعة والتي تتحكم بشـدة الصيوت وضيعفه مما يضفي على العزف طابعاً علمياً جديدا يتميز عن المدارس الأخرى. وقد استمرت هذه المدانه المدرسة إلى يومنا هذا

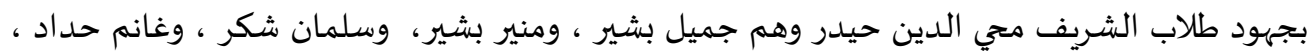

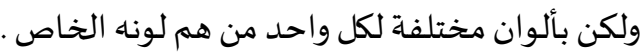
الطريقة التقليدية في تعليم العزف على العود :

تعتمد طريقة تعليم العود التقليدية على المشاهدة، وهي طريقة توارثت من جيل لآخر، إذ تعتمد

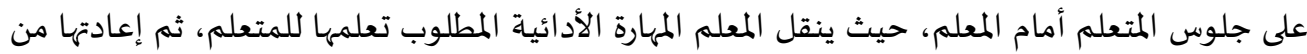
قبل المتعلم، مع تصحيح الأغلاط، وأصيول العزف، وفق أسـاسيات مسكة العود والريشة، وتعليم مبادئ

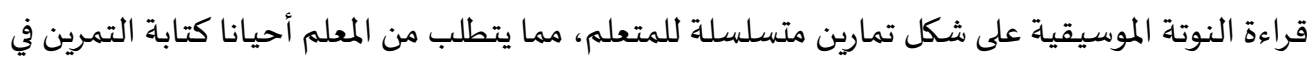

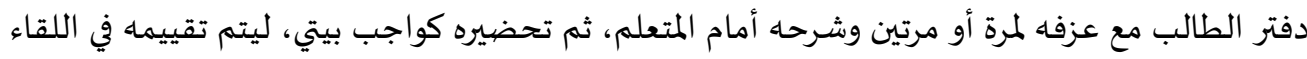
التالي . دول.

وتأسيسا على ما سبق، فقد حدد الباحث ثلاثة مستويات من مجموعة المهارات التعليمية في طريقة تعليم العزف التقليدية على آلة العود، ومن خلال شمولها لأسس أدائية ونظرية، و على النحو الآتي :

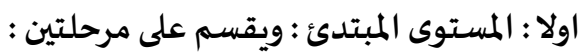
أ- المرحلة الأولى: شملت تعليم العزف على الآلة الموسيقية مع تعليم الاساسيات مثل مسكة الآلة والريشة

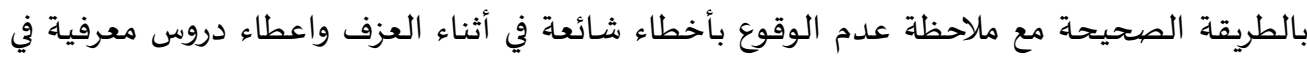

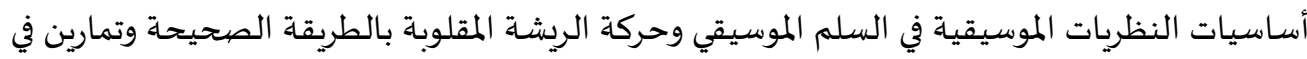
مبادئ قراءة النوتة الموسيقية على السلم الاساس (عجم على درجة دو) . فضلاً عن تعليم بعض المض الأغاني بالطريقة المبسطة .

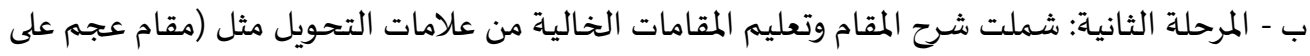

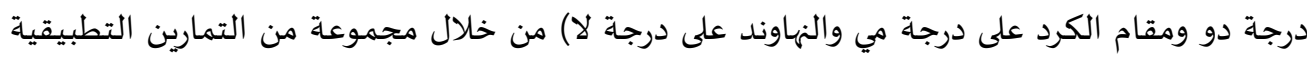

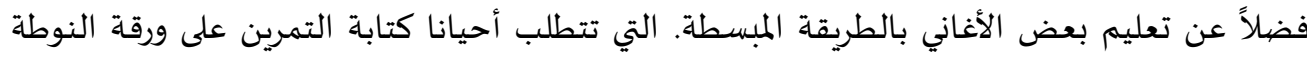
الموسيقية. ثانيا : المستوى المتوسط : ويقسم على مرحلتين :

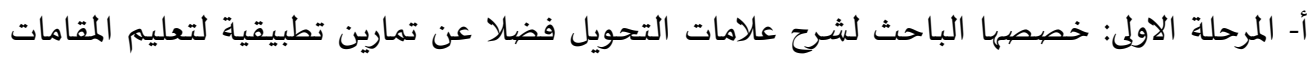

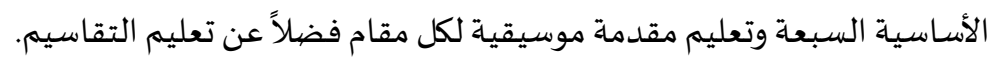

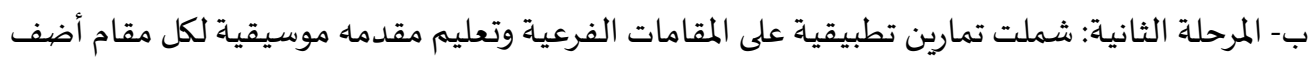
إلى ذلك تعليم التقاسيم . 


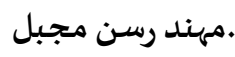
و اقع تدريس آلة العود في المؤسسات التعليمية الموسيقية. مجلة الأكاديمي-العدد 96-السنة 2020

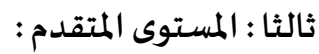

أ. المرحلة الأولى: شملت تمارين تكنيك للأصابع والريشة على سلالم المقامات وعلى شكل أوكتافين صعوداً نزولاً.

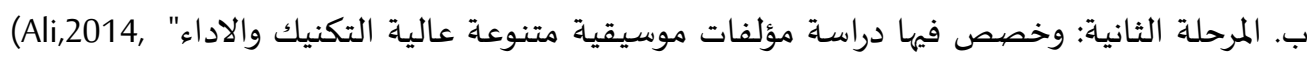

المؤسسات التعليمية الموسيقية في العراق :

نظرا لانتشار الة العود في معظم بلدان الوطن العربي، الذي أدى إلى ظهور كثير من العازفين،

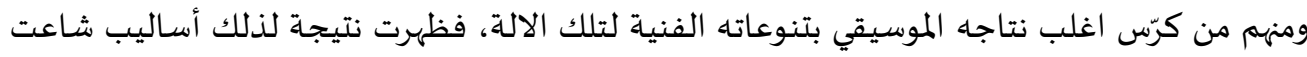

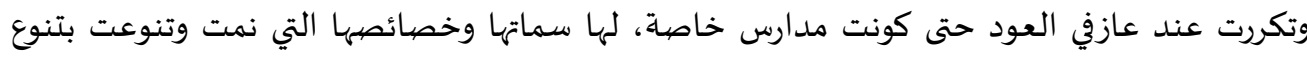

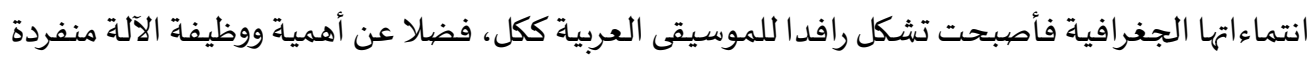

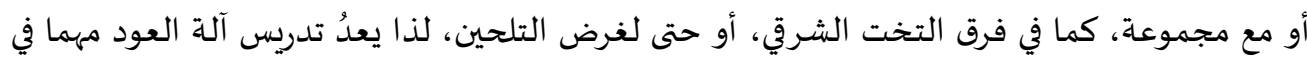

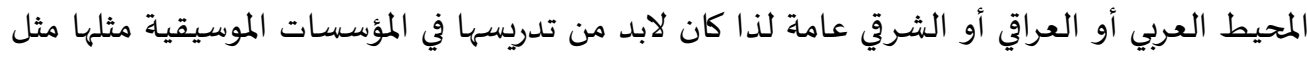

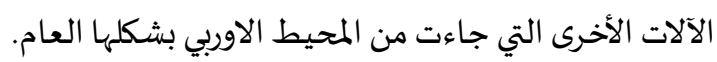

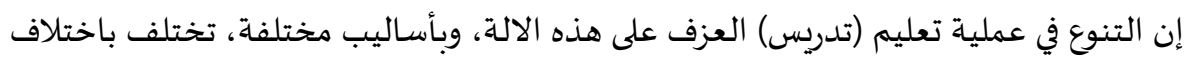

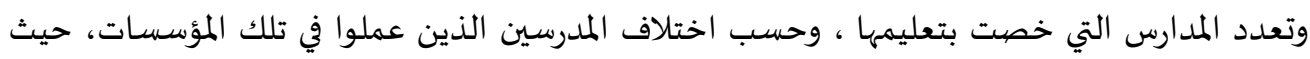

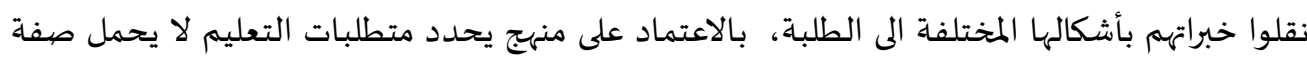

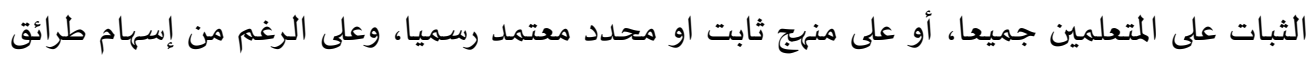

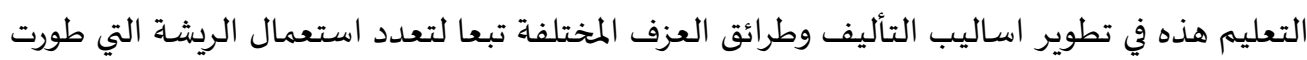
ووسعت ومنحت للعود دورا كبيرا في التعبير الموسيقي.

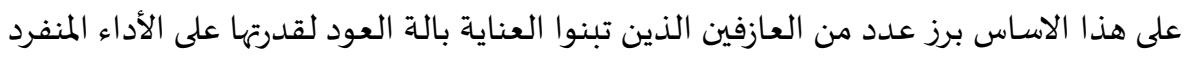

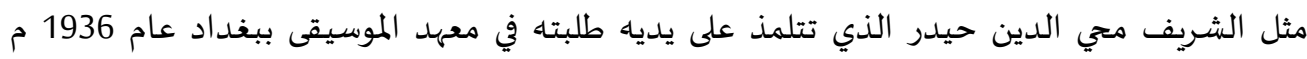

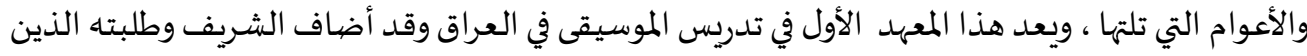

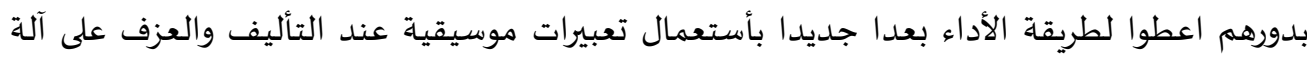

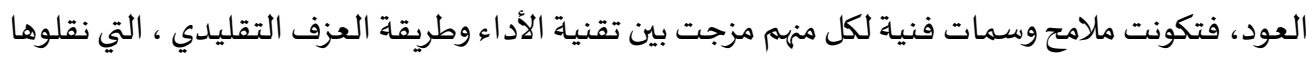

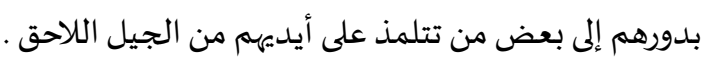

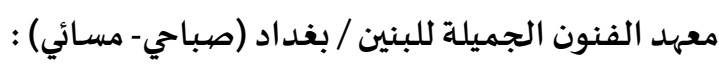

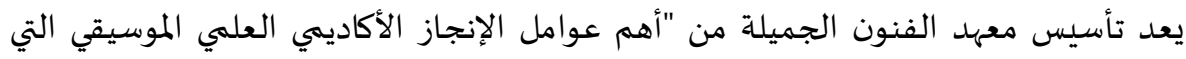

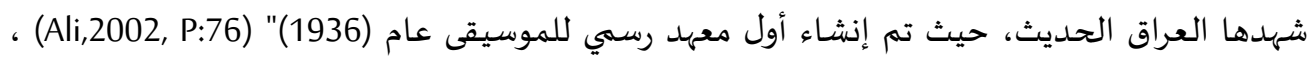

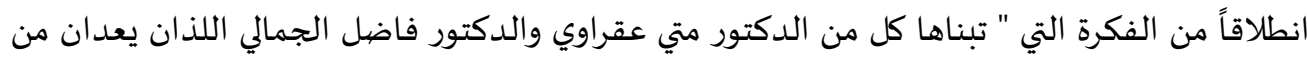

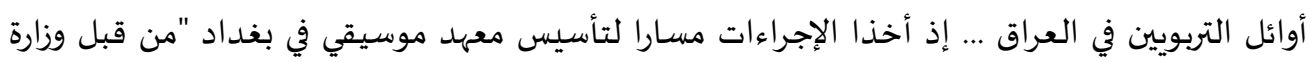

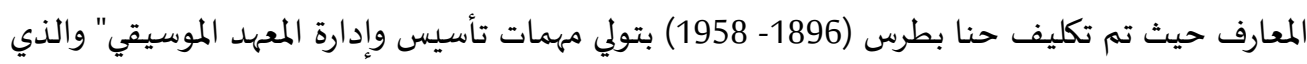


مهند رسن مجبل و اقع تدريس آلة العود في المؤسسـات التعليمية الموسيقية..

ISSN(Online) 2523-2029, ISSN(Print) 1819-5229 مجلة الأكاديمي-العدد 96-السنة 2020 أسهم في دعوة " الشريف مجي الدين حيدر ليقوم بدور المدير و المخطط والأستاذ لهذا المعهد فهو الأول من

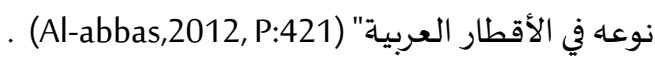

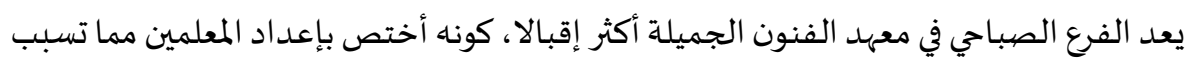

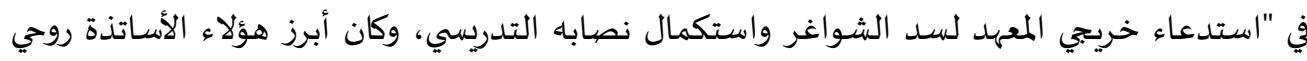

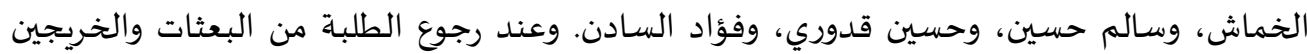

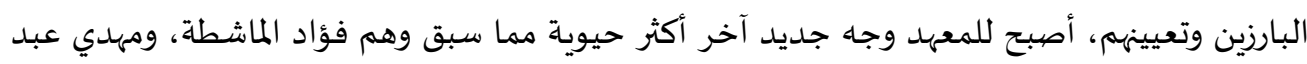

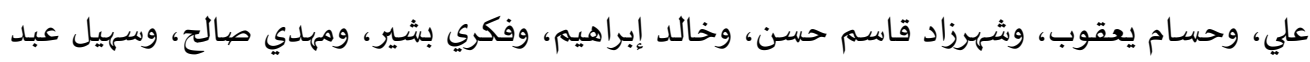

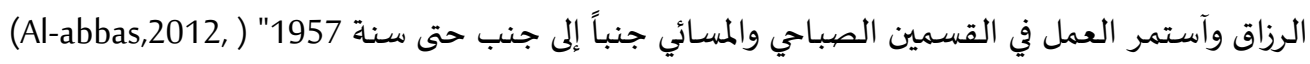
. P:423

اما المواد التي تدرس في القسم اعلاه فهي: تربية صوت ، وتربية سمع ، وموشح ونشيد ، وهارموني

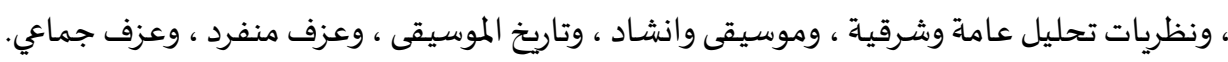

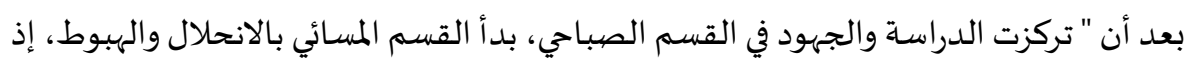

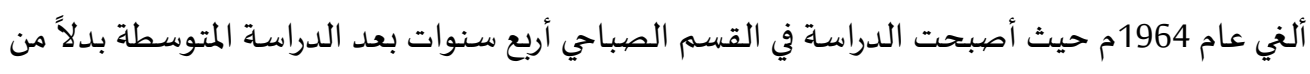

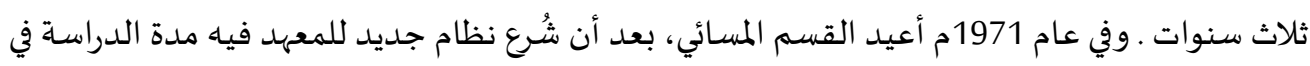

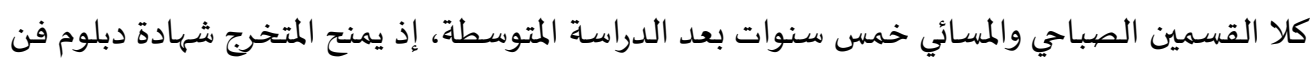

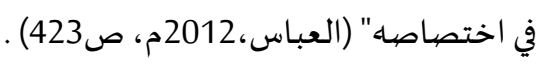
معهد الفنون الجميلة للبنين/ بغداد الرصيافة (مسائي): لقد "تم تأسيس معهد للفنون الجميلة الرصافة في عام الدراسي 2012/2011م. ويتضيمن أقسام القيام

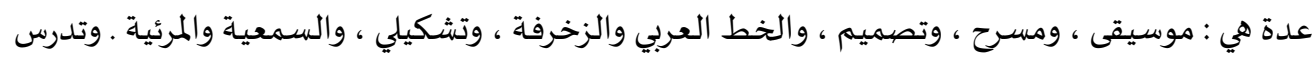

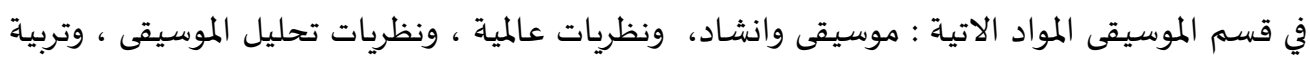

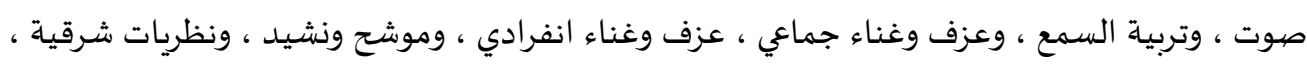

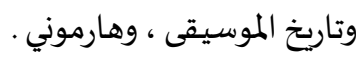

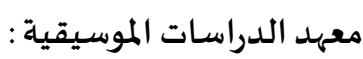

تم تأسيسـا في "خريف عام 1970-1971م، حيث تم إصدار وزارة الإعلام إعلان نشر في الصحف المحلية، وكذلك في إذاعة وتلفزيون بغداد، يدعو فيه عن دعوة الموهوبين في الغناء العراقي إلى الإسراع في

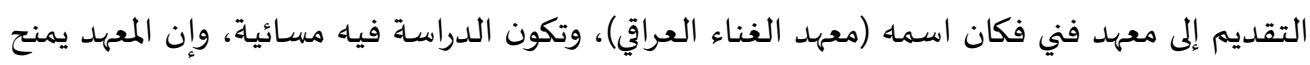

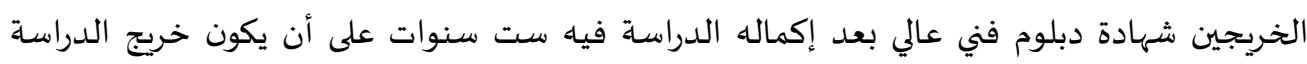
المتوسطة باستثناء شرط العمر (Muhammad,2013, P:2) .

يعد معهد الدراسات الموسيقية هو "أول معهد يعنى بالتراث الموسيقي الغنائي الوطني العربي

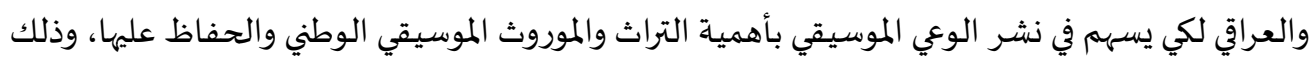

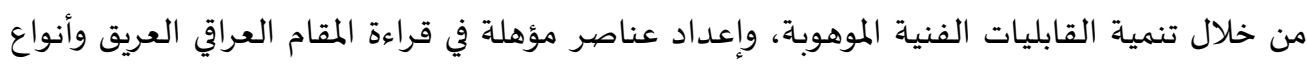

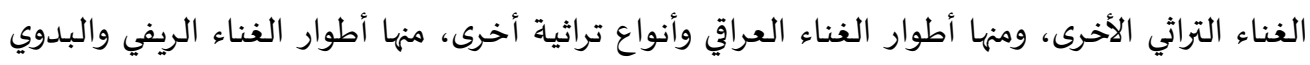


مهند رسن مجبل و اقع تدريس آلة العود في المؤسسـات التعليمية الموسيقية..

ISSN(Online) 2523-2029, ISSN(Print) 1819-5229 مجلة الأكاديمي-العدد 96-السنة 2020

وغيرها من الأشكال الغنائية الموروثة" (Ali,2002, P:105) . إن تسمية معهد الديدية الدراسات الموسيقية هي

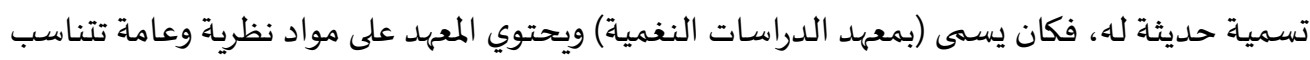

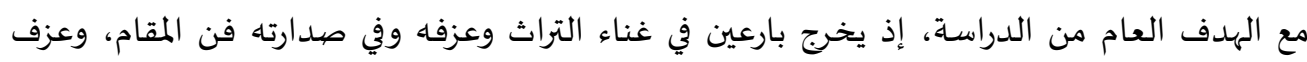

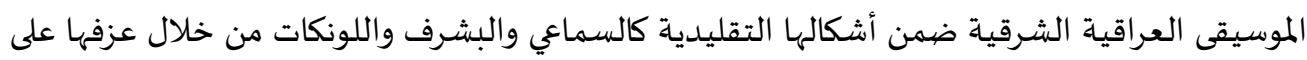

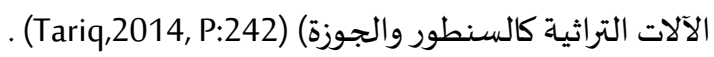

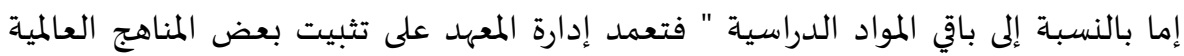

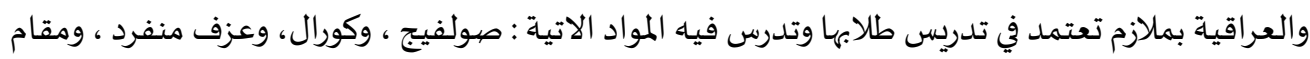

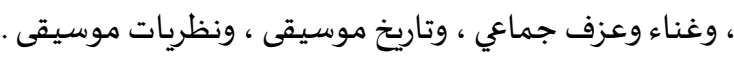

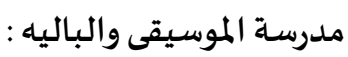
في ستينيات القرن العشرين، تم فتح مدرسة تُدرس الموسيقى تحديداً سنة "1968م تم افتتاح

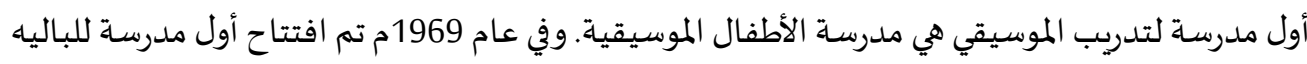

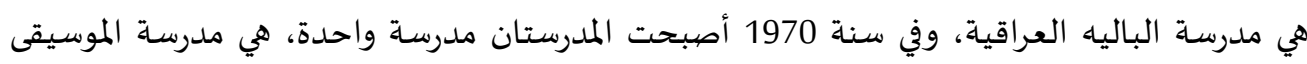
والباليه" (Najiha.1990, P:14) مئه تعد مدرسة الموسيقى والباليه من المدارس الأنموذجية الموجودة في العراق تحديداً في العاصهمة بغداد

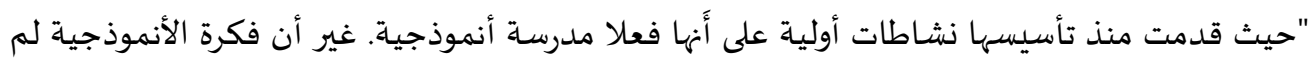

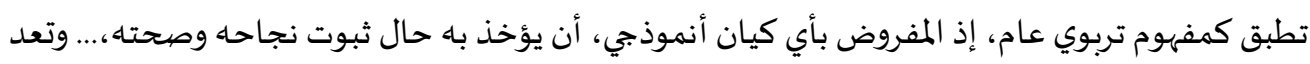
هذه المدرسة الفريدة من نوعها في الشرق الأوسط (Asaad,1974, P:115) .

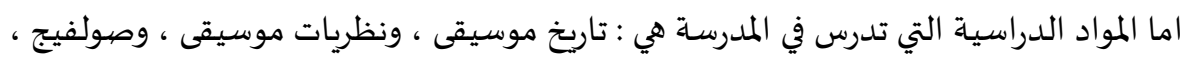

$$
\text { وعتائج الاطار منفرد ، وعزف وغناء جماعي. }
$$

1. من خلال ما تقدم من مواضيع سابقة اهتمت بتاريخ هذه الالة ومدارسها عبر الحضارات القديمة في

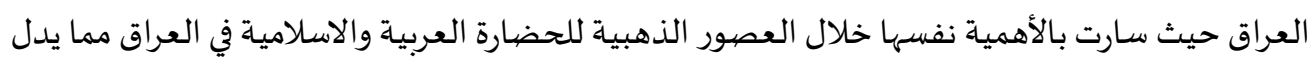

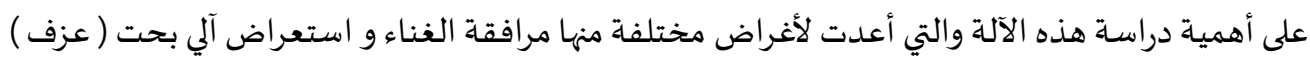
بشكل جماعي او فردي وكذلك أهميتها كونها وسيلة مساعدة لترسيخ وتثبيت الأسس النظرية الموسيقية العربية . 2. ان تميز العراق بهذه الالة لم يكن آنيا وإنما عن طريق تراكم خبرات ثقافية من ناحية اعداد مناهجها

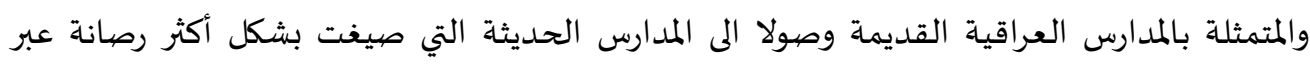

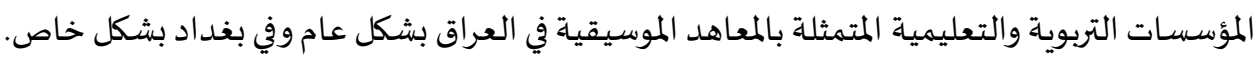

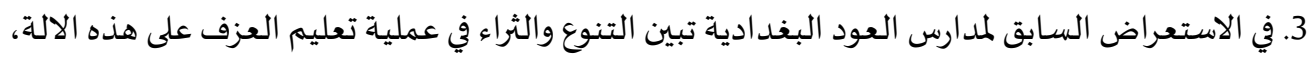
وبأساليب مختلفة حسب اختلاف وتعدد المدارس التي خصت بتعليمها بشكل عام ، حيث لم يختص تعليم العود فيه بأسلوب مدرسة معينة وإنما بأساليب مختلفة حسب اختلاف المدرسين الذين يعملون في

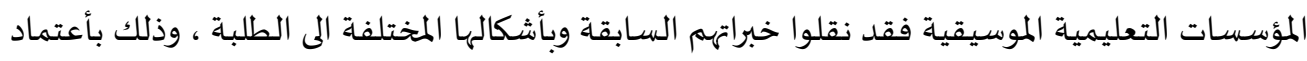


مهند رسن مجبل و اقع تدريس آلة العود في المؤسسـات التعليمية الموسيقية..

ISSN(Online) 2523-2029, ISSN(Print) 1819-5229 2020 مجلة الأكاديمي-العدد 2020 كل قسم من هذه المؤسسات على منهج تدريسي في تحديد متطلبات التعليم وليس على منهج ثابت يقوم

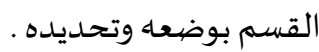

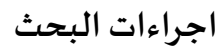

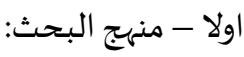
اعتماد المنهج الوصفي (دراسة حالة) لإنجاز هذا البحث.

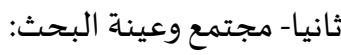
اشتمل على جميع الأساتذة العاملين في المؤسسات التعليمية الفنية المعنية بتدريس الة العودئه ضمنمن المؤسسات الفنية في محافظة بغداد فقط، وهي أربعة مؤسسات فنية، كما في الجدول أدئ أدناه:

\begin{tabular}{|c|c|c|c|}
\hline 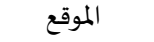 & جهة الانتساب & اسم المؤسسة & ت \\
\hline محافظة بغداد & وزارة الثقافة & معهد الدراسـات الموسيقية & 1 \\
\hline محافظة بغداد & وزارة التربية & 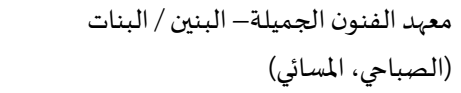 & 2 \\
\hline محافظة بغداد & وزارة التربية & معهد الفنون الجميلة للبنين/الرصافة (مسائي) & 3 \\
\hline محافظة بغداد & وزارة الثقافة & مدرسة الموسيقى والباليه & 4 \\
\hline
\end{tabular}

رابعا - اداة البحث واستحصيال المعلومات:

قام الباحث ببناء اداة لتحقيق هدف البحث، ومن خلال ترتيب فقراته على وفق استمارة اسئلة

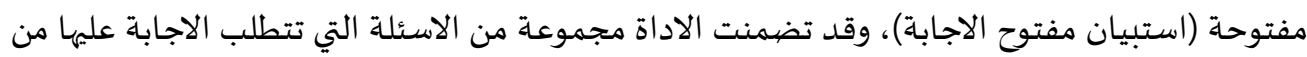

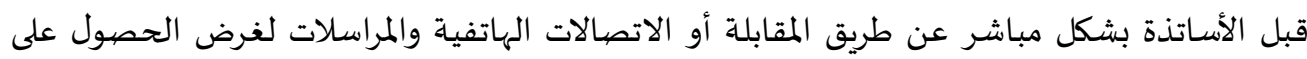

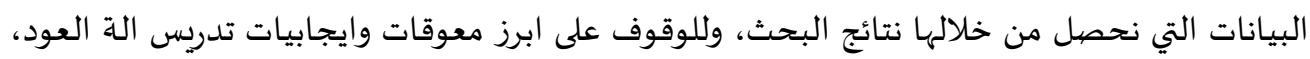
فقد حدد الباحث 6 أسئلة تضمنت من خا يأتي: س 1 / كيف تتم طريقة التدريس؟

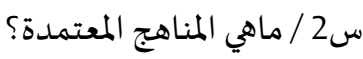
س3 / ماهي التمارين التي تعطى للطلبة؟ س4 / ماهي المراحل التي تقوم بتدريسها؟ س5 / هل هنالك قطعة موسيقية محددة تعطى للطالب في أثناء تدريسـ؟

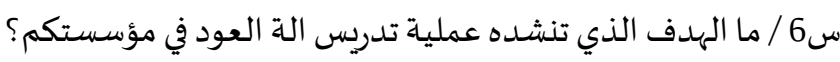

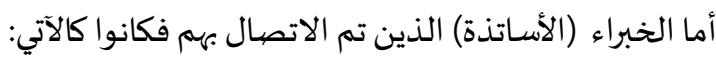

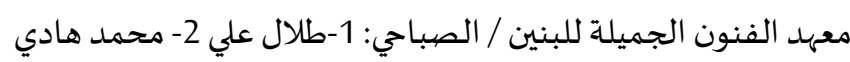
المسائي: 1- مصطفى محمد 2- بلال صبياح

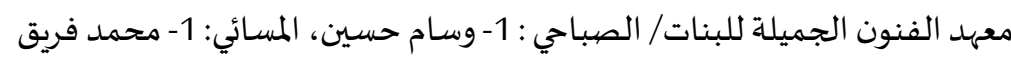

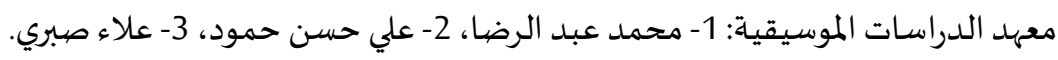

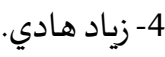
معهد الفنون الجميلة الرصافة للبنين المسائي: 1- عماد محمد فاضل، 2- خالد محمد. 
مهند رسن مجبل. و اقع تدريس آلة العود في المؤسسـات التعليمية الموسيقية..

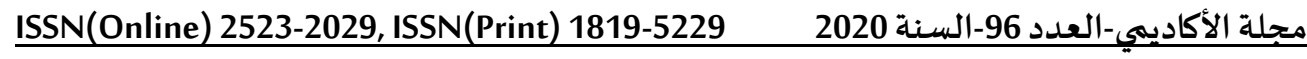
مدرسة الموسيقى والباليه: 1- باسم يوسف 2- احمد سليم 3- ايهاب هاشم 4- جمال ناصير

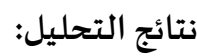

ظهرت نتائج عدة أدت إلى الكشف عن واقع دراسة هذه الآلة في المعاهد الفنية الموسيقية وكانت كالآتي: 1- إن دراسـة هذه الآلة في المؤسسات التعليمية الموسيقية لا يعتمد على منهج علمي أكاديمي كواقع تفرضها

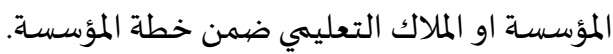
2- بسبب غياب هذا المنهج بشكل عام في الموسيقى العراقية تبين أن أغلب المدرسين يعتمد بشكل كبير على فئل

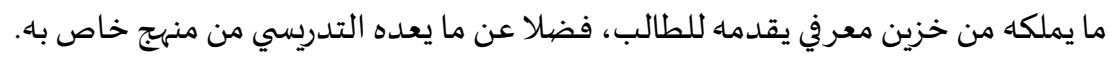

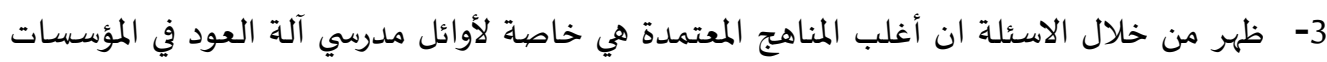
التعليمية، وتشمل: من خلا:

ا- العود وطريقة تدريسه بجزئيه الأول والثاني تأليف جميل بشير.

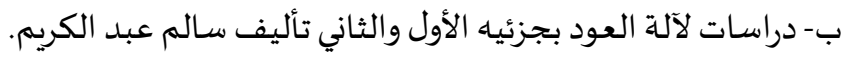
ج- دراسات ومؤلفات موسيقية بجزئيه الاول والثاني تأليف معتز البياتي.

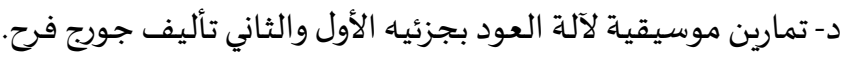
4- يعتمد التدريسي على مقتطفات من المناهج المستخدمة في النقطة السابقة كبداية لتعليم الطالب تورئ العزف.

5- يعتمد المدرس على ميول الطالب تجاه ما يتذوقه من الأساليب الأدائية من خلال خزينه السمعي، في محاولة لتعلم عزفها. 6- اعتماد التدريس الخاص بهذه الآلة وفق ما يدرسـ المختص بهذا المجال، فكان الاختلاف واضحا في عرض المادة وطريقة تدريسها بسبب اختلاف قدرات المدرسين وامكانياتهم التعليمية. 7- ظهر بشكل واضح ان التعلم الذاتي وقابلية الطالب وموهبته الفردية هي أساس بناء الطالب الجيد والمتمكن من العزف على الآلة، من خلال تطوير نفسه بنفسه ومن خلال خبراته القديمة المكتسبة وفية بأشكال مختلفة لم يكن اساسها التدريس وإنما عملت هذه المؤسسات التعليمية على ارشاده نحو الأفضل من دون إسناده بمنهاج يعمل على بنائه او تطويره وإنما بنصائح تعدل وتقوم ما هو متمكن منـه.

الاستنتاجـات:

على الرغم من أن تدريس آلة العود يكون وفق مؤلفات أساتذة العود منهم جميل بشير، وجورج فرح، ومعتز محمد صالح، وسالم عبد الكريم، وحسب ما متوفر منها في المؤسسة، ان اندئ التدريسي لايلتزم

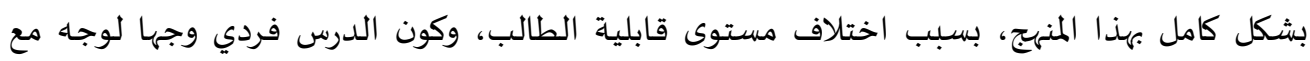

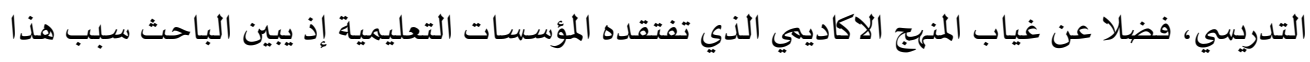
النقص في المنهج هو عدم الاتفاق الكامل بين مدرسي العود، واختلاف مناهجهم، التي تدعو لترشيح منهج 


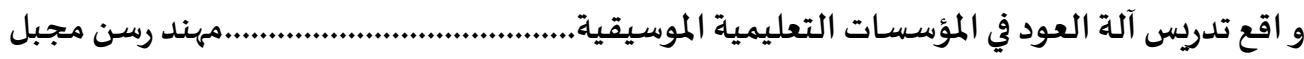

ISSN(Online) 2523-2029, ISSN(Print) 1819-5229 2020 مجلة الأكاديمي-العدد 2020

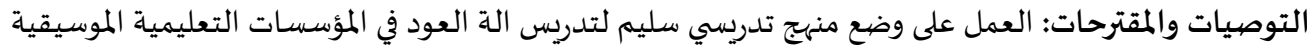

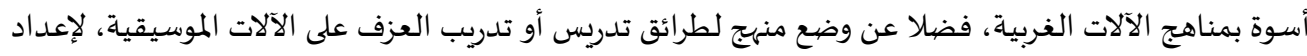

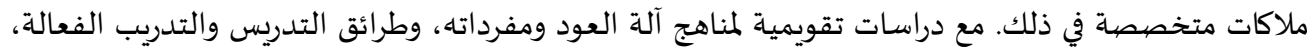

بالاعتماد على دروس مشتركة خلال المنهج الدراسي للمؤسسة.

\section{References:}

1- Elias, Simon Yaqoub El-Khoury: National Standards for Composing Music Education Curricula for Basic Education in the Syrian Arab Republic, research published in the Jordanian Journal, Volume 6, No. 1, 2012AD.

2- Al-Fahdawi, Saleh Ahmad: The Basics of Teaching Musical Education, research published in the Journal of the Teachers College, No. 20, Al-Mustansiriya University, 1999 AD.

3- Ahmed Mukhtar Omar: A Study of Linguistic Voice, Cairo: (World of Books), 19997 AD.

4- A Dictionary of Contemporary Arabic Language, Cairo: World of the Book, 1st edition, 2008 AD.

5- Al-Sudani, Kamal Hassan, Calendar of Musical Education in Institutes of Fine Arts, Unpublished Master Thesis, College of Fine Arts, Baghdad, 2013 AD.

6- Farid, Tariq Hassoun, History of Musical Arts from its inception until the end of the sixteenth century, part 1, House of Books and Documentation, Baghdad, 1990.

7- Youssef, Naseer, Informatics, Education, and Culture, Informatics Symposium in the Arab World, 1st floor, Dar Al-Faris for Publishing and Distribution, Amman, 2002.

8- Arafa, Abdel Moneim, History of Flags of Oriental Music, 1st edition, Anani Press, Egypt, 1947.

9- Al-Abbas, Habib Al-Zahir, Arab Music Theories, Freedom House for Printing, Baghdad, 1986.

10- Ali Hassan Hammoud, playing the oud in the oud through the Internet, unpublished Master Thesis, College of Fine Arts, Department of Musical Arts, Baghdad, 2014.

11- Ali, Abdullah, Music Studies, General Cultural Affairs House, 2002

12- Al-Abbas, Habib Al-Zahir, Manhal, who is wondering about music and singing news in Iraq, Baghdad, Kurdish House of Culture and Publishing, 2012.

13- Muhammad Luqman, Institute of Music Studies, Asala and Ibda, Baghdad, International Center for Studies of Traditional Music, 2013.

14- Farid, Tariq Hassoun, Words on the Musical Amphitheater Lines, Part 1, Baghdad, Iraqi Center for Traditional Music Studies, 2013 CE.

15- Najiha Nayef Hammadi: School of Music and Ballet, Baghdad: (Dar Al-Jamaheb Press), 1990.

16- Al-Abbas, Habib Al-Zahir, Manhal, who is in charge of music and news of singing in Iraq, Baghdad (Kurdish Culture and Publishing House), 2012.

17- Asaad Muhammad Ali, Introduction to Iraqi Music, Baghdad: (Freedom House for Printing), 1974 AD. 


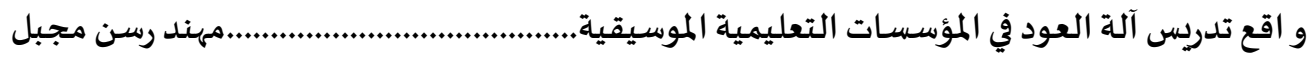

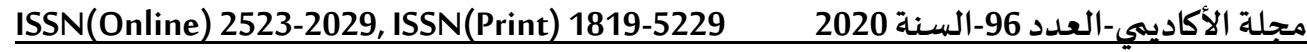

DOI: https://doi.org/10.35560/jcofarts96/379-390

\title{
The reality of teaching the oud in musical educational institutions
}

\section{Muhanad resan megbil ${ }^{1}$}

Al-academy Journal Issue 96 - year 2020

Date of receipt: 17/2/2020.

Date of acceptance: $17 / 3 / 2020$.

Date of publication: $15 / 6 / 2020$

\begin{abstract}
There is no doubt that the oud is one of the most important folk musical instruments in Iraq. It has been known since the ages of ancient Iraq in its form, strings, and the way to play it through the clay number. On them, however, they have participated in showing the instrument the greatest potential and musical aesthetics, and the interested person may be wondering about ways to learn to play this instrument, so the training methods varied between personal interpretations on the one hand and systematic teaching in educational institutions on the other hand, especially that they have received the attention of educational institutions Miya, that which must adopt an appropriate and scientific strategy that accompanies global education projects in modern methods and teaching methods, relying on the curriculum and then the student, and the importance of this aspect must begin to prepare a study on those methods used to teach playing the oud instrument in musical educational institutions Affiliated to the Ministry of Education and Culture in the governorate of Baghdad.
\end{abstract}

Key words: oud, teaching oud, the reality of teaching, musical institutions

${ }^{1}$ graduate student/ College of Fine Arts / University of Baghdad, ula_hussen@yahoo.com 